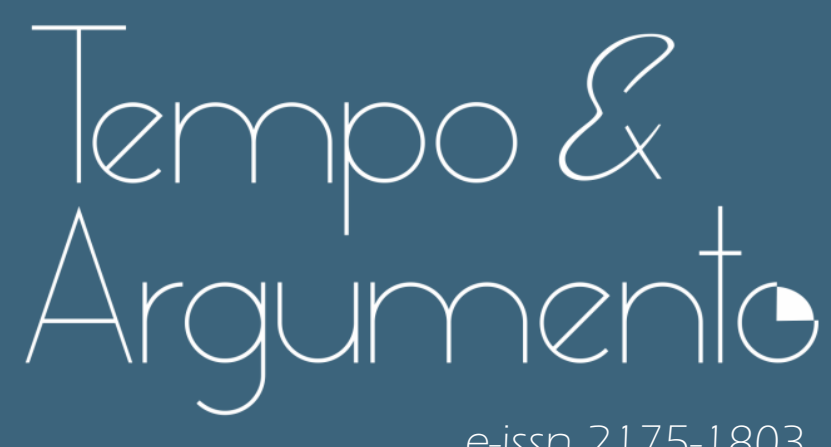

e-issn 2175-1803

\title{
Viajera de tu memoria: reflexiones sobre el uso de las entrevistas en historia de las mujeres
}

- Adriana María Valobra

Doctora en Historia por la Universidad Nacional de La Plata (UNLP).

Investigadora independiente del Consejo Nacional de Investigaciones en Ciencia

y Técnica (CONICET). Docente de la Universidad Nacional de La Plata (UNLP).

Buenos Aires - ARGENTINA

memoria.fahce.unlp.edu.ar/perfiles/ 1377ValobraA.html

indivalobra@gmail.com

(iD) orcid.org/0000-0003-3955-4791

Para citar este articulo (ABNT):

VALOBRA, Adriana María. Viajera de tu memoria: reflexiones sobre el uso de las entrevistas en historia de las mujeres. Tempo e Argumento, Florianópolis, v. 13, n. 33, e0203, maio/ago. 2021.

doi http://dx.doi.org/10.5965/2175180313332021e0203

Recebido: 13/03/2020

Aprovado: 14/03/2021 


\title{
Viajera de tu memoria: reflexiones sobre el uso de las entrevistas en historia de las mujeres
}

\begin{abstract}
Resumen
En este trabajo, abordaré ciertos aspectos que considero relevantes para pensar una historia con fuentes orales. Para ello, me serviré de un conjunto de estudios que han aportado a consolidar los andamiajes de la llamada historia oral a la luz de los aportes conceptuales de las teorías feministas y de género y reflexiones vinculadas a la problemática de clase. Puntualmente, me focalizaré en una dimensión de la ciudadanía política: votar, según la construcción de las mujeres que votaron por primera vez en Argentina en 1951.
\end{abstract}

Palabras clave: Metodología. Entrevistas. Género. Ciudadanía Política. Argentina.

\section{A traveler of your memories: reflections on the Uses of Interviews in Women's History}

\begin{abstract}
In this paper, I endeavor to explain certain aspects I consider relevant for thinking about a history with oral sources. For this, I will use a set of studies that have contributed to consolidate the scaffolding of the so-called oral history under light of the conceptual contributions of feminist and gender theories and reflections linked to the class problematic. I will focus on one dimension of the concept of citizenship: to vote, in the social construction of women who voted in Argentina in 1951.
\end{abstract}

Keywords: Methodology. Interviews. Gender. Political Citizenship. Argentina.

1. Reflexiones de una viajera fascinada

Sólo tú haces de mi memoria una viajera fascinada, un fuego incesante.

(PIZARNIK, 2001, p. 160)

La falta de reflexividad sobre la producción primaria de datos y su utilización en las investigaciones es un problema teórico-metodológico que atraviesa distintas disciplinas sociales y humanas (BURAWOY, 2018). Cientos o 
miles de manuales sobre cómo hacer entrevistas en ciencias sociales no suplen la falta de reflexión concreta, específica, situada; no tanto sobre cómo se debería hacer investigación o cómo la hicieron otros, sino cómo incide el propio hacer en los conocimientos que se producen. Por ello, en este trabajo, realizaré un esfuerzo por explicar ciertos aspectos que considero relevantes metodológicamente para la realización de entrevistas y, en definitiva, para la construcción de una historiografía alternativa. Intentaré incluir dos cuestiones: la reflexión sobre la metodología en el proceso de entrevistas y, finalmente, la construcción de los insumos de mi investigación, los resultados de mi interpretación y cómo incidió mi propia subjetividad limitada con distintas estrategias de control. No intento "objetivar" los acontecimientos, al menos no en el sentido que lo hace el canon positivista que presupone que hay un objeto de estudio y que podemos, por ciertos mecanismos “asépticos", exponerlo racionalmente. Como ya ha sido dicho, esta idea se funda en una falacia, pues quien investiga es un sujeto atravesado por valores, prejuicios y experiencias que, sin duda, inciden en su investigación (HARDING, 1992). Aun si quisiéramos utilizar la noción de objetividad -despejados los halos semánticos de corte positivistapodríamos decir que el primer ejercicio de objetividad que formulo en este ensayo es, precisamente, reconocer que parto de ciertos posicionamientos que no son ingenuos sino que son políticos y que, lejos de invalidar el conocimiento que produzco, más bien lo afirman en cuanto implican asumir esos atravesamientos y someterme a un constante mecanismo de reflexión, no sobre la historiografía que se hizo (o la que otros hicieron), sino sobre la historiografía que estoy haciendo (VASILACHIS DE GIALDINO, 1992).

Puntualmente, me focalizaré en la realización de entrevistas como estrategia de trabajo a partir de la meditación sobre la ciudadanía política de las mujeres. Específicamente, me propongo analizar el proceso de "devenir ciudadanas" que vivieron las mujeres durante el gobierno peronista cuando se sancionó la primera ley nacional de derechos políticos femeninos en la Argentina (Ley 13.010 de 1947). Me propuse percibir el impacto de esa ley en la vida de las personas al tiempo que vislumbrar otras prácticas de subjetivación política y comprender cómo habían vivido esta experiencia las mujeres que habían votado 
por primera vez. Plantearé cómo fue el contacto y cuáles las dificultades encontradas, qué contrato comunicativo establecí con quienes entrevisté, cuál fue el rol que asumí y el que, creo, me otorgaron durante la entrevista y cómo estos factores jugaron en ella.

\section{2. ¿Quién de ellas?}

Cuando comencé mi investigación, en el año 2001, observaba que los estudios existentes omitían todo cuestionamiento sobre cómo se materializó políticamente la ley 13.010 de 1947, primera ley nacional argentina que reconocía a las mujeres el derecho a votar y a ser electas. Me pregunté entonces, cómo se constituyó un nuevo cuerpo de electoras y cómo la ley impactaba en la cotidianidad de las mujeres que, hasta entonces, tenían vedado el derecho al sufragio. Para ello, me pareció pertinente recuperar la impresión de "la gente común" sobre los derechos políticos femeninos, especialmente, entre las primeras votantes. Orienté la búsqueda a personas (en su mayoría mujeres, aunque no de manera exclusiva) que, preferentemente, no hubieran tenido vínculos con los partidos políticos.

No pensé en la entrevista como una manera de darles voz a los sin voz, aunque me parecía una idea seductora pero que prontamente descubrí ingenua pues, en toda investigación social, la voz de la persona entrevistada está intervenida. Tampoco pensé que fuera espontáneo. No hay nada de espontáneo, decía Ronald Fraser (1991), en sentarse -como lo hacía yo, en la sala de una casa o en el bar de un club de tercera edad-y pedirle a alguien -en general, una persona desconocida hasta ese momento- que nos cuente su vida. Menos espontáneo es pretender, a partir de ello, recuperar ciertos aspectos que consideramos pertinentes para analizar la cuestión de la ciudadanía política femenina durante los años 40-50. Volveré sobre esto más adelante.

El primer paso de mi búsqueda fue encontrar personas que no tuvieran militancia y que hubieran participado de la experiencia electoral de noviembre de 1951, primeras elecciones en las que votaron las mujeres a nivel nacional. La cantidad de personas que podían dar con ese perfil era prácticamente inabarcable y limitadas mis posibilidades de acceder a todas. ¿A cuántas 
personas tendría que entrevistar? ¿Era válido el criterio cuantitativo para la historia oral? Pero ¿podía hacer una sola entrevista y pensar que era representativa de un conjunto? ¿O debía hacer cientos? Si lo hacía ¿sería útil? El punto de saturación -ya mentado por Cicourel, entre otros- era el límite “cuantitativo" del trabajo: cuando comenzara a escuchar repeticiones sobre los tópicos, ese era el punto en que podía detenerme (BERTAUX; BERTAUX-WIAME, 1993). Esta premisa me resultó muy útil ya que me permitió comenzar la tarea sin preocuparme por cuánta gente entrevistar. Ello no significa que es cuantificable cuando comienza a haber repitencia de información (aunque esa repitencia, a veces, puede darse cuando se contactan personas que pertenecen a un mismo grupo y han construido un pasado común de sí). Un ejemplo puede ser elocuente. Yo supuse una hipótesis sustantiva, que las mujeres habían vivido el acceso al voto como una ruptura que había significado un momento positivo tanto en su vida privada como en la pública. Pero no fue así. Cuando estandaricé la información de las entrevistas y cuantifiqué las respuestas sobre ciertos tópicos, no pude negar la repetición, pero sólo cuatro mujeres habían sentido lo que yo suponía; el resto, tenía otras opiniones y eran mayoritarias.

La búsqueda inicial de potenciales entrevistadas se conectó con un criterio de selección muy amplio: la edad al momento de la entrevista. Se trataba de identificar mujeres que hubieran votado en las primeras elecciones generales de 1951 y que pudieran expresar su vivencia personal de ese acontecimiento. Mi investigación utilizó como base treinta entrevistas en profundidad a mujeres, doce entrevistas en profundidad a varones, diez entrevistas focalizadas a mujeres y una focalizada a otro varón. Es decir, un total de 53 entrevistas. La muestra, de modesta magnitud cuantitativa, resultó ser significativa en tanto los hechos o casos que aprehendí con ella fueron, a decir de Guber (2009), "pertinentes para dar cuenta de cierto haz de relaciones en un sistema social”. De tal modo, este conjunto de entrevistas lograba integrar "un sistema de significados y de relaciones sociales", por lo que el criterio de significatividad fue fundamental para la selección. Se trató de un grupo de personas de más de 70 años, con diferencias en cuanto a su extracción social e inserción socioeconómica en el período $1945-$ 1955, cuya edad, para 1951, oscilaba entre los 18 y los 35 años, en la primera etapa 
de la adultez. Por razones obvias, no podía entrevistar gente que hubiera tenido más de cuarenta años hacia 1951.

Por otro lado, por una cuestión de accesibilidad, territorialicé la muestra privilegiando personas que, al momento de la entrevista, vivieran La Plata y Berisso, ciudades de la provincia de Buenos Aires, y en la Capital Federal. Aun así, el panorama que me aportaron los testimonios, no se circunscribió a este territorio, o estrictamente a regiones "urbanas", ya que las vidas de las personas entrevistadas habían transcurrido en otras provincias, en el campo, en pueblos y en otras ciudades. Además, fue necesario contemplar que las personas se encontraran en condiciones de mantener una entrevista, en muchos casos, debido a la edad, la misma podía fatigarlas o requería de momentos y condiciones muy precisos, lo que no era una dificultad menor.

Los contactos se fueron resolviendo de diversos modos. Por un lado, entrevisté a personas que no conocía y muy pocas con quienes había tenido algún contacto eventual, sólo una resultó muy cercana a mí. La mayoría eran conocidas de allegadas (de mi madre, de mi abuela, de mis alumnos/as o mis amigas). Por otro lado, me acerqué a un club de jubilados en Berisso en uno de los días de reunión. Allí me presenté y entrevisté a quienes "daban con el perfil” y aceptaron la propuesta. Realicé más de 20 entrevistas a personas no insertas en estructuras partidarias, aunque no utilicé todas para mi investigación: comenzaba a encontrar mi punto de saturación. En el grupo, sólo entrevisté a algunos varones y creo que debería haber entrevistado a algunos más, para poder elaborar ideas más firmes sobre los lazos sociales. De alguna manera, estaba anclada en una historia de mujeres y, aunque no pretendía esencializar a "la mujer", el afán visibilizador jugó en contra de la búsqueda de posibles personas a entrevistar.

\section{Un yo de sujeto cognoscente que se conoce conociendo}

Una vez realizados los contactos, el primer problema fue cómo presentar el tema de investigación. El hecho de declarar que el objetivo de la entrevista se relacionaba con el sufragio femenino se develó como una mala estrategia. Implicó, en primer lugar, perder entrevistadas que rehuyeron hablar del tema 
alegando que no sabían ni se acordaban nada. Se hizo evidente que la negativa se vinculaba a que el acontecimiento estaba unido al gobierno peronista y, aunque a mí me pareciera irrisorio en un principio, muchas personas consideraban que "de eso no se habla". El contexto de realización de las entrevistas, los años 2001 y 2002, fue de una gran sensibilidad política. Por otro lado, en algunas entrevistadas, a la inversa, se notaba la preocupación por ir directamente "al grano", obviando otros aspectos que no consideraban relevantes. Por eso, en las siguientes presentaciones, hice referencia a un objetivo más general: cómo era la vida social, política, económica, en especial, en los años cuarenta y cincuenta. El tema del sufragio apareció como "un tema más" dentro de los que se habían tratado. Noté que, de esa manera, el contacto inicial mejoraba y la conversación se tornaba más fluida. A lo largo de las entrevistas, muchas veces, la persona entrevistada o yo misma volvíamos a especificar el objeto de estudio. La premisa era que supieran que conocer esos aspectos sociales, políticos y económicos me ayudaba a comprender más cabalmente su perspectiva sobre los derechos de las mujeres, que eran mi objeto central de investigación.

La realización de estas entrevistas significó un gran esfuerzo, en parte, por tratarse de personas no habituadas a la experiencia de ser entrevistadas. Mi rol fue cambiando a lo largo de las conversaciones y según quién fuera mi interlocutora. En ese sentido, la idea bakhtiniana de otredad me permitía comprender que había un otro en ausencia, anterior a cualquier contacto que tuviéramos. Estábamos jugando papeles contingentes en la medida en que cada uno se aggiornaba al momento, al otro interlocutor, etc. En esta intersubjetividad descubrí la producción de sentido dialógica (BAKHTíN, 1982).

Un primer ejercicio fue despojarme de lo que había sido mi experiencia anterior en este tipo de acercamiento metodológico. Cuando-con unos cuantos años menos-hice las entrevistas para la tesis de licenciatura, la gente me hablaba como si fuera su nieta, una estudiante a la que podían ayudar. Ese rol me resultó cómodo y lo asumí sin mayores conflictos. Por entonces también estaba embarazada de mi primer hijo y, en retrospectiva, creo que mi estado inspiró a la gente para hablar con más confianza, a distenderse de un modo que no creo 
haber logrado en otras oportunidades. Estas impresiones de mi experiencia anterior me llevaban a actuar del mismo modo, sin embargo, eran nuevas situaciones y yo también era otra: seis años mayor, madre de dos hijos e historiadora... nadie me habló como si fuera su nieta, era una profesional haciendo su trabajo, aunque me reconocieran como integrante de otra generación.

Comprendí que yo provocaba la situación de entrevista, la que construía el testimonio como un tipo de fuente particular y que, en ese encuentro con el otro, que era buscado por mí como investigadora con el fin de construir un "saber profesional", de ninguna manera me despojaba de las experiencias de clase, de género y de edad que provocan desplazamientos en nuestras propias posiciones y repercuten en la construcción de las fuentes (PORTELLI, 1991). Asumo también que después de cinco meses de reposo y apenas nacido mi segundo hijo, la tarea de entrevistar me tomaba en un momento de especial emotividad.

Al elegir el formato de historia de vida, lo más común y menos conflictivo parecía ser solicitarle a quienes entrevistaba algunos datos de "filiación" fáciles de responder: nombre, edad, fecha de nacimiento, lugar... Era una manera, supuestamente relajada, de comenzar la entrevista. Así lo hice un día en el que entrevisté a una señora oriunda del sur de la Argentina. Ella intentó articular una respuesta, su voz se quebró y se puso a llorar. Después de un momento, comenzó a balbucear que la ponía triste acordarse de su infancia porque eran tan pobres y hacía tanto frío, que de lo que más se acordaba era del frío. También lloré, podía evocar recuerdos semejantes de mi vida. Pero ella necesitaba consuelo y tomé esa coincidencia de nuestras historias para ayudarla. La abracé, le alcancé un poco de agua y comencé a contarle que cuando yo era chica también éramos muy pobres y empecé a reírme de que teníamos la pared "empapelada" con el papel de forro de los cuadernos, que de un lado de la cocina se caía el techo y nadie quería ir a comer ahí, que teníamos una cama matrimonial para cinco... Ella sonrió, un poco sorprendida de que pudiera reírme de eso. Se fue tranquilizando. Le propuse no hacer la entrevista, pero quiso hacerla. Tal vez, habíamos logrado zanjar la "dosis de angustia" en la catarsis de ese llanto (ALONSO, 1994). En etnografía, alguien podría hablar de la empatía 
como estrategia. Pero no se trataba de una estrategia deliberada para mejorar mi Llegada al campo. Más bien, entiendo que mi posibilidad de comprender de qué me hablaba la mujer que estaba entrevistando cuando recordaba la pobreza que le dolía en la memoria -porque, antes, le había dolido en el cuerpo- se debía a que en el campo están nuestra capacidad racional y nuestras "cargas civiles, personales e históricas" (GUBER, 1969); y yo tenía mi propia memoria de la pobreza y se parecía mucho a la suya.

La mayoría de las personas a las que había entrevistado hasta entonces habían sido extremadamente pobres en su infancia, pero a diferencia de esta mujer, junto con muchas anécdotas que ejemplificaban su pobreza, recordaban con bastante alegría esa época: "Mi infancia fue pobre pero muy linda”, me había dicho una señora. En cierto modo, las rememoraciones más crudas del pasado se suavizaron para quienes, merced a la movilidad social, se había trastocado su condición de clase. En otros casos, ese pasado se presentaba en sus memorias de manera vívida pues, como han señalado algunos autores, es esta memoria la que define a ciertos sujetos pertenecientes a una clase: a través de una clara percepción de un antagonismo social que merece que se conmemore (FENETRESS; WICKHAM, 2003, p. 155).

Aprendí mucho de esa experiencia, a partir de entonces, no volví a quebrarme de ese modo en otras entrevistas aun cuando me conmoví profundamente. Comprendí que había una prioridad que no podía descuidar: la persona a la que entrevistaba. Las preguntas más simples podían despertar emociones muy intensas, recordar devolvía sentimientos angustiosos, incluso traumáticos. También, comprendí que yo no era una terapeuta o una psicóloga, pero tenía que tener en cuenta cuál era la mejor manera de acompañar a quien entrevistaba en caso de que algo como lo que relaté volviera a suceder (RICKARD, 2000). Había un lazo emocional con estas personas aunque fueran desconocidas, una sensibilidad que me unía a ellas.

El lazo emocional, afectivo y familiar estuvo presente en otras situaciones. Mi abuela fue una de las primeras personas a las que entrevisté en mis primeros pasos en la historiografía. Desde muy chica, su voz y la de mi mamá habían introducido la tradición oral en mi vida, pues ambas tenían costumbre de narrar 
historias en la oscuridad del cuarto, donde sus voces parecían un bálsamo antes de dormir. La historia de amor de mi abuela me inquietaba: un amor contrariado, paciente, jubiloso, triste... anudado en algunos pequeños momentos con el puente que se levantaba el 17 de octubre de 1945, con las crisis económicas, con los avatares de la cotidianeidad... Pero cuando la entrevisté para mi investigación me resultó impactante escucharla porque muchas de las historias que me había narrado en la infancia cobraban una perspectiva distinta en esta nueva visita que hacíamos a su vivencia. El 17 de octubre de 1945, aquel día en que se levantaba el puente, mi abuela vio, maravillada, pasar a la muchedumbre desde la puerta de su casa en Avellaneda y sintió deseos de sumarse a aquella manifestación. Su novio - mi abuelo - no se lo había permitido y mi bisabuela vigilaba que cumpliera su indicación. Asimismo, el orgullo con el que antes me había mostrado el medallero que el abuelo había obtenido por su destreza como bailarín, se desvanecía. Los bailes de mi abuelo no eran para alegría de mi abuela, que no iba con él, sino que se quedaba en la casa, cuidando a los hijos, rumiando su enojo. Ella creía que el voto iba a cambiar esas situaciones y, aunque no fue así, sintió que tenía la fuerza para confrontar esos hechos incluso cuando no pudiera cambiarlos. Escuchar todo esto fue la primera interpelación a mis propias identificaciones experienciales, con mis sentimientos, con la propia historia personal que había construido desde chica, en base a sus relatos, algunos edulcorados y otros de los que, a partir de entonces, comprendí en sus implicancias. Para mí, esta entrevista involucró un ejercicio de compromiso y distanciamiento, al estilo de lo planteado por Norbert Elías (1990, p. 67) respecto del "grado de dominio sobre uno mismo y el grado de dominio sobre el proceso", ambos, "interdependientes y complementarios" entre sí.

\section{De la entrevista como construcción social}

Luego de estos comentarios, quisiera diferenciar algunas cuestiones. Un aspecto es que la situación de entrevista no es espontánea. La mayoría de la gente, en los primeros tramos de la entrevista, no parecía interesada en querer decir algo que nadie supiera o en contar su versión de los hechos. Fue más bien durante el proceso de entrevista que fueron ganando su posicionamiento y se 
constituyeron como portadores de una verdad que el resto desconocía. Entonces, aparecía la frase "yo te voy a decir cómo fueron las cosas". Se componía allí un otro social más amplio y abstracto, que se encarnaba en mi escucha y en una potencial escritura. Las miradas ilusionadas de contarme "la verdad de la milanesa" (sic) y las sonrisas cómplices, a la hora de relatar lo que se creía una revelación, invocaban una trascendencia de ese yo individual, personal, a un yo social, a través de lo que Joutard (2007, p. 117) ha llamado "la memoria orgullosa”.

Como señala Robin (1996, p. 65-66), “la espontaneidad es falsa. No porque el sujeto no quiera ser auténtico, quiera mentir; al contrario, hay un gran esfuerzo por decir la verdad". Su falsedad está en la ilusión referencial -que no es más que una ilusión narrativa- que nos hace pensar en una palabra "auténtica", fuera del poder, y que presenta a esa historia que se cuenta como si se "desarrollara delante de nosotros". Mi supuesto era que no había una verdad a develar, ni el discurso de quienes entrevisté se me reveló transparente; no me apropiaba "directamente" de él con el grabador o con mis notas. Las estrategias incluyeron tanto la atención flotante, la libertad de asociación libre del informante como la categorización diferida. No significa que todas mis entrevistas hayan sido no directivas. Este fue un aprendizaje también, no para hacerme invisible, sino para incorporar tanto mi subjetividad como la de la persona entrevistada como herramienta legítima de investigación (GUBER, 2009). En ese proceso, en las entrevistas y en relación a mi tema de investigación, me informaron de una serie de procedimientos electorales y narraron hechos de la vida política, a la vez que construyeron una ilusión biográfica de reafirmación de una identidad social posible (BOURDIEU, 1985).

Por otro lado, el contrato comunicativo que se establece en la entrevista nos coloca frente a distintas situaciones. En general, en estas entrevistas oscilé entre la empatía y una actitud de vigilia. Es que mientras más me confundía o me caía en la narración del otro, menos interesante se hacía el diálogo, porque terminaba mimetizándome con esa historia. Si no planteaba ciertos interrogantes ante el relato de esa vida, que me fascinaba en su singularidad, muchas preguntas quedaban sobrevolando. Tener una guía de pautas generales me ayudó 
a organizarme y a no perderme. En efecto, la entrevista tenía un objetivo puntual: mi investigación. En este sentido, la guía de pautas me ayudaba a pensar en mis objetivos, en el recorrido que había planteado. También me resultó muy útil escribir las preguntas, pensar de qué modo indagar ciertas cuestiones, qué palabras usar. Redactar la guía de pautas era un modo de posicionarme en el juego de la entrevista y funcionó como un cuestionario abierto. No era una grilla que completaba con una cruz, sino que delineaba los aspectos que, de antemano, me resultaban interesantes para relevar y, a la vez, me permitía abrirme a la escucha. La guía también facilitó la comparación posterior de ciertos tópicos.

En esas entrevistas encontré algunos elementos comunes. En primer lugar, les pregunté sobre el anonimato y les expliqué que mantendría su decisión sobre ello por lo que, si no lo deseaban, no era necesario que me dieran su nombre y apellido, de manera que se sintieran más libres a la hora de emitir su opinión. Sin embargo, al comenzar la entrevista, indicaban su nombre y apellidos completos como si encontraran en ello un modo de trascender su cotidianeidad anónima. El nombre recuperaba también la peculiaridad de su relato, pues nadie había vivido lo que ellas y como ellas. En este sentido, algunos objetos materializaban su identidad nominal. En efecto, el documento de identidad fue traído a la entrevista. Algunas, incluso, me decían que era el primero y, que si quería, podía usarlo para ilustrar mi investigación. Esto evidenció la formalidad que le atribuían al documento de identidad (ZONABEND, 1981) y cómo la cuestión del anonimato no se zanja de una vez, sino que se va construyendo en la entrevista en el contrato comunicativo y en el vínculo de confianza. Ello supone, a su vez, otras complejidades y situaciones atendibles. Por ejemplo, algunas personas que volví a ver me decían que hubiera sido mejor que pusiera sus nombres porque, al fin y al cabo, quién iba a saber que ellas eran quienes habían hablado. Una noción de la trascendencia se hacía cada vez más patente al final de sus vidas.

\section{Donde hablan los silencios: género y política}

Otros aspectos aparecieron en el momento de realización de la entrevista a personas que nunca habían sido entrevistadas. Algunas no hablaban, 
contestaban monosílabos, había largos silencios. Otras hablaban en exceso de situaciones deshilvanadas para mí. Si bien no había ido a buscar la "ilusión biográfica" -como diría Pierre Bourdieu (1997) - de coherentes acontecimientos, a veces no entendía cómo habíamos llegado a ciertos momentos. Mi actitud, sin duda, no siempre fue la más adecuada ante estas situaciones. Por momentos me ponía ansiosa y repreguntaba, intentaba inquirir, para seguir el diálogo. Es decir, terminaba hablando yo. Por el contrario, en otras ocasiones, desplegaba otras estrategias: apenas si esbozaba un "ajá", intervenía tipo eco o complementando la frase o me entregaba al silencio esperando respuesta. También ocurría que, si la persona entrevistada hablaba a sus anchas, el problema estaba en encontrar un recodo para pedir aclaración sobre alguna cuestión; pero si, lograda una pausa, yo intentaba retomar, no siempre se compensaban los cabos sueltos.

No era extraño que aparecieran momentos en los que las personas entrevistadas se impacientaban y me preguntaban si me servía lo que decían; o que ellas no sabían tanto. Es decir, aparecía lo que Joutard (2007, p. 116) llamó “la memoria modesta”. En general, volvía a dejar en claro que a mí me interesaba su vida y que nadie mejor para contármela. En esos momentos, sentía que no había sabido "llevar" la entrevista y me disculpaba por cualquier incomodidad. En efecto, la situación de entrevista me obligaba a pensar sobre cómo presentarme, cómo dirigirme, cuándo intervenir o no, dominar mi propia impulsividad, adecuarme a las necesidades de la entrevista.

En este aspecto, la entrevista evidenciaba, todo el tiempo, relaciones de poder que suponían distintas posiciones de los interlocutores, de sus relaciones, de su estatus social. Además, no sólo aparecía la evocación del entrevistado, sino la de la entrevistadora, con las particularidades que ello supone, y acompañada por un conjunto de asimetrías que devienen del reconocimiento de un estatus, de la clase, del género, etcétera. Aunque el ejercicio del poder va cambiando durante el diálogo, en las entrevistas a personas con una "vida común", la licencia para preguntar acerca de sus vidas, pensamientos, sentimientos o cuestiones personales, sobre las que nunca antes se habían puesto a pensar o habían tenido que poner en palabras, hacía que las asimetrías se manifestaran, y que, por 
mucho cuidado que pusiera en el modo de preguntar, no dejara de convertirme en una entrometida, esperando una respuesta.

Por otro lado, las personas entrevistadas tenían estrategias de evasión si no querían contestar sobre algunos temas en particular. Por ejemplo, un elemento interesante para mi investigación es que cuando las mujeres alegaron desconocer cuestiones de política, convocaban a sus maridos a explicarme. Aunque siempre les dije que lo importante era lo que ellas me dijeran, aunque no fuera exacto, insistían en llamar a sus esposos. Lo que, en principio, comenzó siendo una interrupción a la entrevista, al repetirse, comencé a pensarlo como un dato para mi investigación. Las mujeres se desautorizaban para hablar de política y se apoyaban en el conocimiento de quien las había acompañado prácticamente toda su vida. Así, el "yo" de las entrevistadas evidenció el sentido dialógico y, en la recurrencia de ciertos modismos, expresiones y representaciones, podía encontrar una hegemonía discursiva/ideológica acerca de ciertas esencializaciones del "ser mujer", que funcionaron como modelos ideales a los que ellas se ajustaron por oposición a los de los varones (PASSERINI, 1996).

La mayoría de las veces, sin embargo, los maridos tampoco podían decir mucho más que ellas, aunque tomaban la palabra con más soltura en relación con los temas públicos. En este caso, jugaba la experiencia de socialización que construye la masculinidad más referenciada en lo público; una construcción, sin duda, también subordinada respecto de otras masculinidades que se consideraban hegemónicas (CONNEL, 1997) y que habían subordinado a estos varones en el pasado, en particular, en base a la condición de clase. De hecho, buena parte de los varones entrevistados eran reconocidos públicamente como ciudadanos -conjunto del que explícitamente se excluía a las mujeres-, aunque habían sido también públicamente seccionados en sus atributos de ciudadanía en tanto se les imponía a quién votar mediante el fraude y la coerción, en particular, en los años 30, cuando algunos habían realizado sus primeras votaciones. En este sentido, ellos también tuvieron cierta dificultad para rememorar hechos vinculados a las cuestiones políticas. 
Los varones, en muchos casos, me devolvieron interlocutores que me decían lo que creían que yo quería escuchar como mujer de otra generación, que trabajaba. Esto se traducía en una presentación de ideas igualitaristas respecto de varones y mujeres. Éstas, sin embargo, eran de corto aliento, pues rápidamente aparecían observaciones contradictorias acerca del rol de la mujer y las diferencias sexuales en las que las jerarquías condensaban una ubicación subordinada de las mujeres, en especial de las esposas, en el ámbito doméstico. Debo reconocer que me incomodé ante ciertos comentarios pero, como ha señalado Ramsay (1996, p. 135), un "yo investigadora”, construido durante la entrevista, me permitía ubicarme en un rol diferente a mi "yo feminista" que, asimismo, estaba en proceso, por lo que traté de no coartar al entrevistado.

Muchas de las mujeres entrevistadas analizaron la subordinación de la mujer. Algunas se referían a su propia vida; otras, remitían a las de sus amigas o conocidas. En general, no se habían dado cuenta de esa sumisión en los momentos pasados o, habiéndola percibido, no pensaron en modificarla. Las indexaciones acerca de los roles femeninos implicaban siempre la sujeción a una figura masculina. Ellas habían experimentado esa subordinación en un padre que no las dejaba estudiar, un hermano que las habilitaba a casarse, un marido que no las dejó seguir trabajando; pero también asumían que, ellas mismas, acordaban con estas situaciones, en tanto era lo que se esperaba de ellas. Esa expectativa social se confundía, en la mayoría de los casos, con lo que deseaban $y$, en otros, con la aceptación, pese a que su anhelo fuera reprimido. Estos recuerdos fueron movilizadores para varias de las mujeres entrevistadas pues, a la distancia, pensaban que les habría sido muy útil seguir estudiando, no haberse casado con esa persona o haber seguido trabajando. También narraron sueños irrealizados, frustraciones... Como contrapeso de esas circunstancias, solía aparecer una frase: “y bueno... me casé, tuve a mis hijos...”. Retomando a Paul Ricoeur (2006), en la identidad narrativa de estas mujeres, la ipsiedad, la promesa de sí mismas, terminaba resolviéndose en una mismidad, la identidad fija en un sentido tradicional, una identidad casi isomórfica con los modelos sociales impuestos de feminidad. 
En otros casos, como en el de las mujeres que se dedicaron a una profesión liberal, apareció la soltería y la ruptura con el modelo femenino de la maternidad. En ellas hubo silencios sobre la situación porque lo tomaban con "naturalidad" o porque no habían podido resolver el hecho de no cumplir con los mandatos sociales.

Respecto de la construcción de sí que realizaron las entrevistadas, el discurso tuvo algunos momentos que se podrían clasificar como institucionales (estereotipos familiares, políticos, etc.) y derivaron a planos más personales, a medida que se desarrollaba la entrevista y se iban soltando y sintiendo más cómodas o compenetradas con su propio discurso. No creo, ingenuamente, que las entrevistadas lograran olvidar la situación en que inscribían su relato, pero sí que la tensión del primer momento de la entrevista se fue relajando a medida que avanzaba el diálogo. Asimismo, en algunos casos, construyeron imágenes heroicas de sí mismas o se insertaron como partícipes de situaciones históricas “importantes”, aunque realmente no hubieran estado allí. Por ejemplo, fue común que hablaran sobre el 17 de octubre o sobre el renunciamiento de Evita como si hubieran estado entre quienes participaron de esos hechos cuando, en realidad, se referían escenas que, a posteriori, habían visto en documentales o en televisión y revelaban una memoria mediatizada (GINZBURG, 2004). A partir de esto, me pregunté por qué estas personas hubieran querido estar en esos eventos, por qué me hablaban como si hubiesen estado.

En varias ocasiones, se preocupaban por precisar datos históricos que contextualizaran sus propias vidas, aunque muchas veces el anclaje temporal no fuera tal. Esos momentos, nos colocaban frente al carácter ficticio de la situación: se perdía el hilo que se iba tejiendo a medida que avanzábamos en la entrevista; como diría Portelli,

"una historia se cuenta naturalmente no cuando se adhiere a una cronología objetiva sino cuando se aparta de ella para incorporar sentido y conceptos o juicios subjetivos. Sólo un esfuerzo muy cuidadoso, artificial, puede mantener hechos y opiniones separados". (PORTELLI, 2008, p. 47)

Pero incluso cuando confundían años, lugares y nombres, la memoria se presentaba descarnada como un proceso de creación de significados (PORTELLI, 
1991). En un determinado momento, también, incluí tanto preguntas sobre contenido como preguntas sobre la actitud, y en otros, me decidí a aportar el dato que preocupaba, a fin de permitir la fluidez que se había perdido intentando recordarlo. A veces, mi propia memoria fallaba o cometía errores, sin duda, y eso confundía a mis entrevistadas. En un momento de la vida donde las personas mayores pueden tener problemas para recordar, los "hechos seguros" eran necesarios para que se relajaran sobre sus propios recuerdos y su testimonio. ¡Qué reprobación me generaba descubrir que había sido yo quien había cometido errores que no ayudaban a su recuerdo! Podía ser muy dura conmigo misma ante mi propia humanidad y el proceso de devenir historiadora (todavía suelo serlo).

En relación con las consecuencias de la sanción de la ley 13.010 sobre su condición de ciudadanía, las entrevistadas presentaron dos posiciones: las que la percibieron como algo estrictamente político, o bien, quienes la consideraron como una ciudadanía ampliada, en la que incluían los derechos políticos y sociales. A partir de los posicionamientos en torno de la ciudadanía definí tres agrupamientos vinculados, además, a cuestiones de clase y vivencias de género. El bloque mayoritario incluyó mujeres marcadas por una apropiación altamente positiva de los derechos de ciudadanía, los cuales se apegaron a la acción de votar. Este bloque estaba compuesto por mujeres de clase obrera y media (tanto amas de casa como docentes y empleadas administrativas). Otro, minoritario (sólo una mujer), valoraba negativamente los efectos de la ley 13.010, pues los conectaba con el relajo de la identidad femenina. En las antípodas de este último, aunque también minoritario, otro grupo, que incluyó a cuatro mujeres trabajadoras de distintos sectores- que consideraban que la adquisición de derechos políticos conllevaba alcances sociales que, fundamentalmente, incluían la posibilidad de romper con las situaciones de subordinación vividas por ser mujeres.

\section{Lo que queda de mí...}

La experiencia de realización de estas entrevistas me permitió reflexionar sobre la dimensión genérica y de clase, y aprehender el sentido relacional en las entrevistas, aportando a la comprensión del proceso de ciudadanización, no sólo 
desde lo que se imponía a través del estatus, sino también desde lo que significaba la dimensión subjetiva de esa condición, su apropiación, algo que, en la literatura sobre el tema, no se había tratado de elucidar.

He intentado alejarme de la redacción de un listado de ingredientes y procedimientos del buen hacer para llegar al "happy end" de "cómo lograr una buena entrevista". No abandono la pretensión explicativa o la interpretativa por la descriptiva, pienso que una y otra están completamente imbricadas. Me he propuesto construir una narrativa histórica más comprensiva del modo en que se construyen los procesos temporales y cómo son reconstruidos a lo largo del tiempo. Del mismo modo, mi trabajo con entrevistas ha tratado de superar el simple relato biográfico, acontecimental, ordenado, e incluso sobredimensionado, para tratar de recuperar la complejidad de un destino individual en el proceso social y, al hacerlo, contribuir al conocimiento histórico (AGUIRRE ROJAS, 2000).

Reflexionar sobre el proceso de entrevistar me ha llevado a cuestionar las visiones lineales con las que, también, se pueden analizar los procesos en función de la memoria, la clase y el género. En primer lugar, en las entrevistas a las que me referí he destacado la incidencia que tuvieron en el modo de recordar el pasado los cambios en la condición de clase, así como también una tendencia, en varias entrevistadas, a considerar que sus esposos como varones- tenían un conocimiento más cabal de la política, aún cuando esto no se constatara.

En otro orden, la incidencia de mi propia constitución como sujeto cognoscente, he reconocido que mi entelequia no se cultiva independientemente del cuerpo, que el deseo forma parte de mis aprendizajes, de mi forma de apropiarme del saber, de aprehender el mundo. Estoy convencida de que no puede haber conocimiento sin deseo; más aún, no pueden pensarse conocimiento y deseo como pares opuestos (HARAWAY, 1991). Incluso, si la subjetividad puede ser la que nos lleva al error, al equívoco, a interpretaciones inexactas, en fin, a una mala investigación -como dirían quienes creen que con los estudios cuantitativos eso no sucede-, considero que nuestra subjetividad es también la que intensamente nos compromete en el trabajo y nos permite los 
mejores logros. Se trata de logros que tienen un hilo emocional para conectarnos con esos sujetos que indagamos, es nuestra sensibilidad frente al dolor o la alegría de aquellas personas la que también late en nuestra investigación y nos motiva a saber y a comprender.

Por eso me permito cerrar estas consideraciones con una evocación personal. Mi abuela falleció en julio de 2012. Su memoria se había acomodado en la tibieza del recuerdo del abrazo de sus padres, a quienes frecuentemente llamaba. Cuando la visitaba, ella ya no recordaba mi nombre o quién era, pero yo aún sabía quién era ella para mí. No volví a escuchar la cinta de aquella entrevista, probablemente porque su voz todavía repiquetea dentro mío. Si acaso lo necesitara, pondría ese viejo cassette para escucharnos reír juntas o recrearía una y otra vez ese tiempo compartido y todas las personas que ella trajo a mí. Su memoria me llevó a cabalgar el tiempo montada en su melena de fuego, me convirtió en una viajera, como el verso de Alejandra Pizarnik con el que comencé este ensayo. De hecho, me permito reescribirlo para resituar el sentido que las entrevistas tuvieron en mi propia constitución como historiadora.

Sólo tu memoria hace de mí una viajera fascinada, un fuego incesante.

\section{Referencias}

AGUIRRE ROJAS, Carlos Antonio. La biografía como género historiográfico. Algunas reflexiones sobre sus posibilidades actuales. In: SCHMIDT, Benito (ed.). Lo biográfico: perspectivas interdisciplinarias. Santa Cruz Do Sul: Edunisc, 2000. p. 9-48.

ALONSO, Luis. Sujeto y discurso: el lugar de la entrevista abierta en las prácticas de la sociología cualitativa. In: DELGADO, Juan; GUTIÉRREZ, Juan (coords.). Métodos y técnicas cualitativas de investigación en ciencias sociales. Madrid: Síntesis, 1994. p. 225-240.

BAKHTíN, Mikhail, Estética de la creación verbal. México: Siglo XX, 1982. 
BERTAUX, Daniel; BERTAUX-WIAME, Isabelle. Historias de vida del oficio de panadero. In: MARINAS, José; SANTAMARINA, Cristina (comps.). La historia oral: métodos y experiencias. Madrid: Debate, 1993. p. 231-250.

BOURDIEU, Pierre. ¿Qué significa hablar? Madrid: Akal, 1985.

BOURDIEU, Pierre. La ilusión biográfica. In: BOURDIEU, Pierre. Razones prácticas, sobre la teoría de la acción. Barcelona: Editorial Anagrama, 1997. p. 74-83.

BURAWOY, Michael. Prefacio: ciencia y reflexividad. In: PIOVANI, Juan Ignacio; TERRA, Leticia Muñiz (comps.) ¿Condenados a la reflexividad? apuntes para repensar el proceso de investigación social. Buenos Aires: CLACSO- Biblos, 2018. p. 12-15.

CONNELL, Raewyn [Robert]. La organización social de la masculinidad. In: VALDÉS, Teresa; OLAVARRÍA, José (ed.). Masculinidad/es: poder y crisis. Santiago de Chile, ISIS-FLACSO, 1997. n. 24. p. 31-48.

ELÍAS, Norbert. Compromiso y distanciamiento: ensayos de sociología del conocimiento. Barcelona: Península, 1990.

FENETRESS, James; WICKHAM, Chris. Memoria Social. Madrid: Frónesis-Cátedra Universitat de Valéncia, 2003.

FRASER, Ronald, La formación de un entrevistador. In: SCHWARZSTEIN, Dora (comp.). La historia oral. Buenos Aires: CEAL, 1991. p. 131-155.

GINZBURG, Carlo. Memoria y globalización. Revista Historia, Antropología y Fuentes Orales, Barcelona, n. 32, p. 29-40, 2004.

GUBER, Rosana. El salvaje metropolitano: reconstrucción del conocimiento social en el trabajo de campo. Buenos Aires: Paidós, 2009.

HARAWAY, Donna. Simians, Cyborgs, and Women: the reinvention of nature. Londres: Free Association Books, 1991.

HARDING, Sandra, Feminism and methodology. Milton Keynes: Open University Press, 1987.

JOUTARD, Philippe. Memoria e historia: ¿cómo superar el conflicto? Revista Historia, Antropología y Fuentes Orales, Barcelona, n. 38, p. 115-122, 2007.

PASSERINI, Luisa; THOMPSON, Paul; LEYDESDORFF, Selma. Gender and memory. Nueva York: Oxford University Press, 1996. 
PIZARNIK, Alejandra Quién alumbra. In: POESÍA COMPLETAS. Barcelona: Lumen, 2001. p. 160.

PORTELLI, Alessandro, ¡Absalón, Absalón: la historia oral y la literatura. In: Pozzi, Pablo; NECOCHEA GRACIA, Gerardo (comps.). Cuéntame cómo fue: introducción a la historia oral. Buenos Aires: Imago Mundi, 2008. p. 59-72.

PORTELLI, Alessandro. Lo que hace diferente la historia oral. In:

SCHWARZSTEIN, Dora (comp.). La historia oral. Buenos Aires: CEAL, 1991. p. 36 51.

POZZI, Pablo. Introducción. In: POZZI, Pablo; NECOCHEA, Gracia (comp.).

Cuéntame cómo fue: introducción a la historia oral. Buenos Aires: Imago Mundi, 2008. p. 3-12.

RAMSAY, Karen. Emotional labour and qualitative research: how i learned not to laugh or cry in the field. In: STINA, Lyon; BUSTFIELD, Joan (eds.). Methodological imaginations. Basingstoke: Macmillan, 1996. p. 131-146.

RICKARD, Wendy. Historia oral, trauma y tabú. Revista Historia, Antropología y Fuentes Orales, Barcelona, n. 23, 2000.

RICOEUR, Paul. Sí mismo como otro. Madrid-Buenos Aires: Siglo XXI editores, 2006.

ROBIN, Regine. Identidad, memoria y relato: la imposible narración de sí mismo. Buenos Aires: Secretaría de Posgrado Facultad de Ciencias Sociales: Oficina de Publicaciones del CBC, 1996.

VASILACHIS DE GIALDINO, Irene. Métodos cualitativos I: los problemas teóricoepistemológicos. Buenos Aires: CEAL, 1992.

ZONABEND, François, ¿Por qué nominar? In: LEVI-STRAUSS, Claude (org.). La identidad. Barcelona: Petrel, 1981. p. 289-321.

Universidade do Estado de Santa Catarina - UDESC

Programa de Pós-Graduação em História - PPGH

Revista Tempo e Argumento Volume 13 - Número 33 - Ano 2021 tempoeargumento@gmail.com 